\title{
Students' Views on Physics Teaching at a Distance in the Context of COVID-19 Pandemic
}

\author{
Constantina Stefanidou ${ }^{{ }^{*}}$ \\ (D) 0000-0002-2509-7764
}

Kyriakos Kyriakou 1

(D) 0000-0003-3390-9889

\section{Achilleas Mandrikas ${ }^{1}$}

(D) 0000-0003-3606-9723

loanna Stavrou ${ }^{1}$

(1) 0000-0003-3772-0784

\section{Constantine Skordoulis 1}

(1) 0000-0002-8748-1489

${ }^{1}$ Department of Primary Education, National and Kapodistrian University of Athens, Athens, GREECE

*Corresponding author: sconstant@primedu.uoa.gr

Citation: Stefanidou, C., Kyriakou, K., Mandrikas, A., Stavrou, I., \& Skordoulis, C. (2022). Students' Views on Physics Teaching at a Distance in the Context of COVID-19 Pandemic. European Journal of Science and Mathematics Education, 10(3), $284-297$. https://doi.org/10.30935/scimath/11880

\section{ARTICLE INFO}

Received: 25 Jan 2022

Accepted: 5 Mar 2022

\section{ABSTRACT}

This study aimed at mapping high school students' views from several schools of Athens on physics teaching at a distance that took place due to COVID-19 pandemic during the school year 2020-2021. For this purpose, 197 students completed a questionnaire that included 14 closedended questions and two open-ended questions. Findings revealed that most students had a negative view on physics distance course and particularly they emphasized on problems related to the home environment, to inter-connection, to lack of teacher-student, and student-student communication, to decreased concentration and to decreased experimental activities. However, several students found and pointed out some positive elements from the long period of distance education that referred either to the teaching of physics or to general topics. Such positive elements are the increased use of audio-visual material, which contributed to the understanding of the concepts and processes of physics, and which could be adopted in the teaching of physics more broadly, and not only in the distance education.

Keywords: physics distance education, COVID-19 pandemic, students' views

\section{INTRODUCTION}

The COVID-19 pandemic, from the first moment of its appearance affected education at all levels. According to data from the European Union (Di Pietro et al., 2020) as well as recent UNESCO data, since February 2020, 191 countries have taken measures to universally suspend the face-to-face learning process at all levels of education, affecting 1.5 billion learners (UNESCO, 2021).

The suspension of the face-to-face educational process was accompanied by a combination of synchronous and asynchronous distance learning. Even though distance learning has been an effort to ensure the continuity of the learning process, at the same time, a number of problems emerged, mainly related to the quality of the learning process. Most difficulties were related to internet access, lack of infrastructure (Di Pietro et al., 2020; Sari \& Nayir, 2020; UNESCO, 2021), to the conditions that existed in students' and teachers' home environment, to the inherent difficulties of the laboratory courses such as those of science (Center of 
Research and Documentation of Secondary Education Officials, 2021) but also to difficulties faced by students in terms of self-discipline and motivation (Ferraro et al., 2020; Radha et al., 2020).

Greece is one of the countries with the longest and most uninterrupted period of school suspension of operation both in primary and secondary education (Center of Research and Documentation of Secondary Education Officials, 2021). Especially, regarding the high schools (Lyceums) of some areas such as Attica, they were in lockdown from 7 November 2020 to 12 April 2021. Exceptions were the special education schools, which operated normally during this period (Center of Research and Documentation of Secondary Education Officials, 2021).

In the present study, K-10 students' views on physics distance teaching are investigated. COVID-19 pandemic posed a rapid transition from face-to-face teaching to the use of technology for online teaching. Both teachers and students faced the challenge of distance education with no particular preparation or curriculum adaptation. In this context, students' views matter as they are the participants and the receivers of the whole situation and they have not been investigated in depth.

\section{LITERATURE REVIEW}

Distance education is a term that includes several educational approaches based on the use of technological means and differs from face-to-face education because students and the teacher do not meet in a physical classroom (Gewin, 2020). Synchronous distance learning refers to the type of education in which individuals involved in the learning process interact at the same time, whether in different locations, through digital technology (Watts, 2016).

An important component of synchronous distance learning is students' engagement with the learning process and the interaction between each other (Gray \& Diloreto, 2016; Martin \& Bolliger, 2018; Muzammil et al., 2020). Students' involvement in the learning process is directly dependent on the interaction. As a result, there is a strong concern for distance learning, especially in terms of the lack of live interaction between teacher and students. This concern has led many researchers to investigate effective practices to keep students constantly involved in the learning process in a distance learning environment (Lemay et al., 2021; Meyer, 2019). Students' active engagement in the learning process in distance learning is related to the relationships between classmates, between students and teachers and students' motivation such as scores and grades (Muzammil et al., 2020; Watts, 2016). Moreover, during COVID-19, related research revealed and highlighted several challenges in distance education such as difficulties in internet access, lack of infrastructure, classroom management, teachers' and students' behavior, and lack of distance education training (Sari \& Nayir, 2020).

Although there is a lot of literature that investigates the aspects of distance learning, there is not enough research on students' views on particularly physics distance teaching. If we consider the emergency remote instruction during the school year 2020-2021 worldwide, and in Greece in particular, it is worth exploring students' views and the factors that justify these views.

\section{RESEARCH METHODOLOGY}

\section{Research Question}

The research question of the present study is, as follows: What are the Greek high school students' views on physics teaching at a distance during the emergent distance education due to COVID-19 pandemic? Specifically, the question is analyzed in the students' opinion on the following axes:

a. the quality of the inter-connection and the general conditions in students' home environment,

b. the content of the subject,

c. teacher-student and student-student communication and teaching practices, and

d. personal engagement and involvement of every student during physics distance teaching. 


\section{Sample}

The research sample is convenient and consists of $197 \mathrm{~K}-10$ high school students from 20 public schools in the prefecture of Attica to which the research team had access. The questionnaire was initially given in 20 physics classes, each of which had about 20 students, so 400 students, of whom 197 answered, i.e. a percentage of about $50 \%$. These students had been taught physics during the last two school years, mainly at a distance. Specifically, during the previous year (2019-2020) they were taught face-to-face from September to March, remotely until June and face-to-face again for just 15 days until the end of the school year in June 2020. For the school year 2020-2021 face-to-face teaching took place only for one month at the beginning of the school year and about a month at the end.

The criteria for choosing K-10 students are related to the fact that until K-10 level all students in Greece follow the same subjects, with no opportunity of preferences according to future studies. In other words, until $\mathrm{K}-10$ level, physics is part of the general core of the compulsory curriculum and is not treated by students according to their career interest.

\section{Data Collection}

A questionnaire was created by the authors and used as a research tool that contained 14 closed-ended questions in a Likert scale 1-5 or 1-3 and two open-ended questions to highlight the qualitative characteristics of the research. The questions (items) are created and structured in four categories, according to the above mentioned axes which the research question is analyzed to:

a. the quality of the inter-connection and the general conditions in students' home environment (three questions),

b. to the content of the subject (three questions),

c. teacher-student and student-student communication and teaching practices (five questions), and

d. personal engagement and involvement of every student during the distance physics education (five questions) (see Appendix A).

The questionnaire was digitally created and distributed electronically accompanied by a letter to students and parents. Students answered the questionnaire anonymously, from their home outside of class hours.

Regarding the validity of the questionnaire, it is provided by the fact that all questions are related to students' views on distance physics education (content validity) and vice versa, the questionnaire includes all aspects of distance physics education, as they are classified in the four categories mentioned above. Moreover, the questionnaire is thoroughly tested by two experts, experienced high school teachers. They both agreed on the content validity of all sixteen items (Polit \& Beck, 2006), which means that in a 4-point scale ( $1=$ not relevant, $2=$ somewhat relevant, $3=$ quite relevant, and $4=$ highly relevant) they both gave a rating of either 3 or 4 . As a result, all sixteen items had an item content validity index (I-CVI) of 1.00. Regarding the $\mathrm{CVI}$ for the entire scale (S-CVI), which is the proportion of items given a rating of 3 or 4 by both exerts involved, it was calculated 1.00. Finally, it was followed by clear instructions, written for high school students to explain them how to complete the questionnaire.

\section{Data Analysis}

Regarding the closed-ended questions, they were sorted based on the pre-determined answer grades for each question and recorded in tables. Regarding the open-ended questions, qualitative content analysis method was used to analyze the data (Mayring, 2015). Participants' answers in the open-ended questions were the content units. The first author-coder, after indexing students' answers, worked through the material and formulated codes, converting large masses of data related to what students liked most in physics distance teaching (item 4.4) and what they did not like at all (item 4.5) into smaller, more manageable segments (codes). The texts for analysis were given to a second coder along with the analytical rules such as units, coding agenda, category definition, and level of abstraction for inductive formation. The inductive categories were established by the two coders, the first two authors, with calculated Cohen's kappa 0.8 , which is adequate according to Mayring (2000). The points of disagreement with the second coder were recorded by a third 


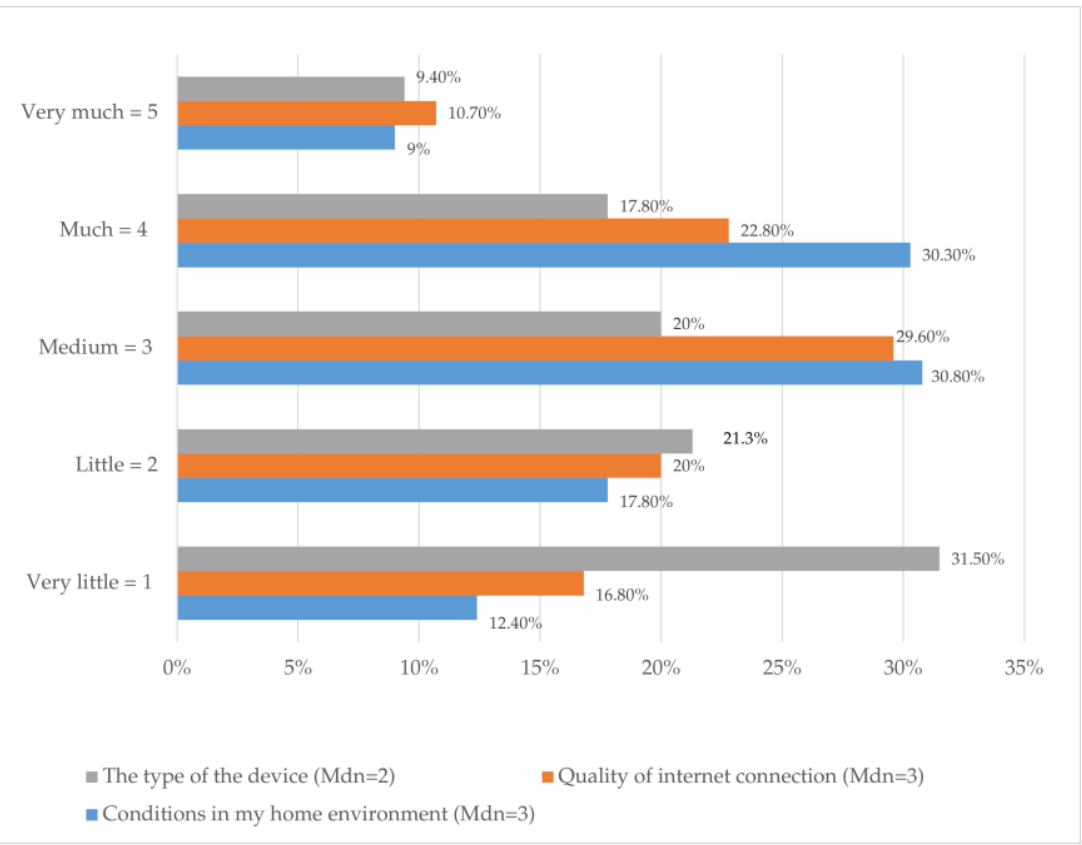

Figure 1. Factors that affected students' views on physics teaching at a distance

coder. Quantitative steps of analysis, i.e. percentages, the so-called descriptive statistics, helped quantify the findings and provide a clearer picture of students' views on distance physics education.

The trustworthiness of this research study was checked by implementing accordant quality criteria: credibility, transferability, dependability, and confirmability. Peer debriefing was used to increase the credibility of the data analysis. Particularly, a qualified impartial colleague reviewed and assessed the methodology of the research, the emerging and final categories, and the findings of the study. Transferability is established by researchers' giving a full and detailed description of the context, so as readers to make informed decisions about the applicability of the findings to other situations (Lincoln \& Guba, 1985). Regarding dependability and confirmability, an outside person reviewed and examined the process and the data analysis in order to ensure that the findings are consistent and could be repeated.

\section{Limitations}

Data for this research were collected from a limited number of high school students. The inherent bias in convenience sampling (Hedt \& Pagano, 2011), due to under-representation of subgroups in the sample, does not allow trustworthy inferences to be made about the intended population.

\section{RESULTS}

\section{Regarding the Quality of the Inter-Connection and the General Conditions in Students' Home Environment}

The students were asked whether the prevailing conditions in their home environment, the quality of their internet connection and the type of device they used to connect influenced their view of physics distance learning. The answers are given in Figure 1.

Among the three factors, the conditions of the home environment in which the student was trying to connect to the online lesson had the biggest impact (39.3\% by adding the answers "much" and "very much"), followed by the connection problems (33.5\%), and finally the type of device (27.2\%).

\section{Regarding the Content of the Subject}

In Figure 2, students' views on how the number of experimental activities differentiated during distance learning compared to the physical class are presented. A percentage of $33.5 \%$ answered that the number of experimental activities has not changed at all. However, $14.2 \%$ of the students found little differences in the 


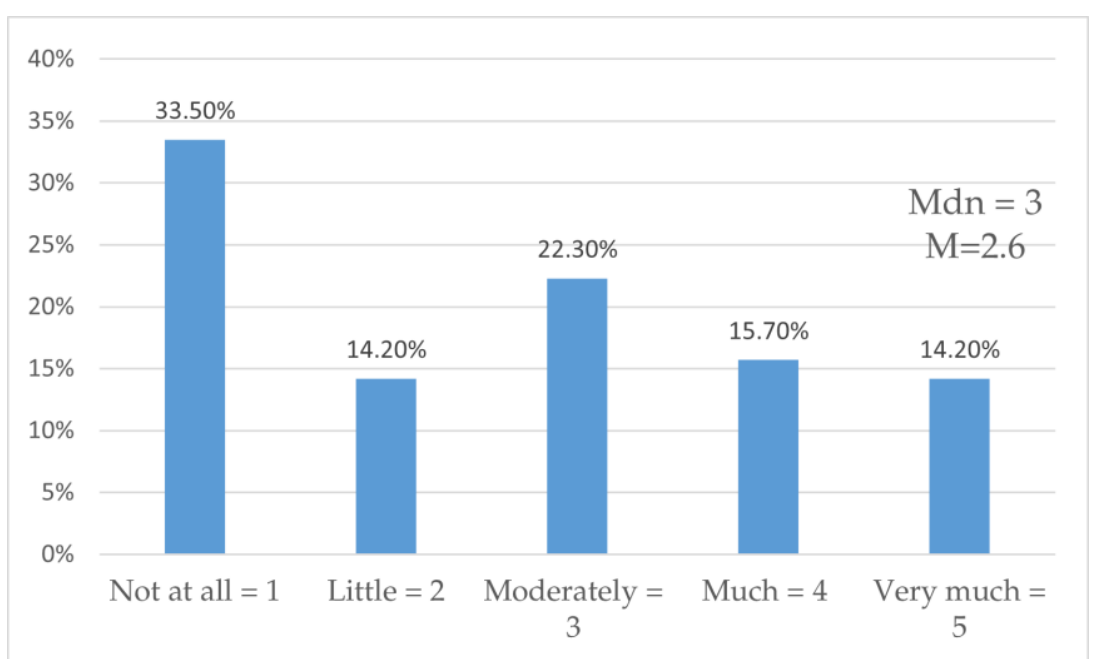

Figure 2. Change in the number of experimental activities during physics teaching at a distance

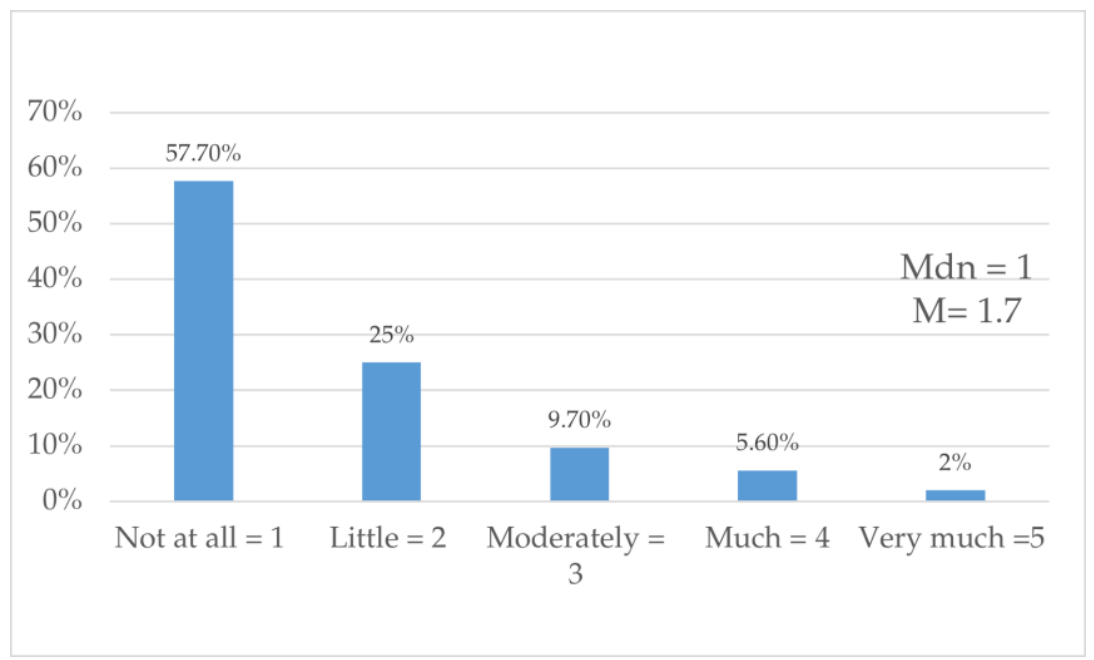

Figure 3. In what extent did physics teaching at a distance help you making your own hypotheses and experimentally control them than face-to-face teaching?

number of experimental activities and $22.3 \%$ found that the number of experimental activities moderately changed. Finally, almost 30\% (15.7\% and 14.2\%) of the students found a lot of differences in the number of experimental activities between distance teaching and face-to-face teaching.

In Figure 3, students' views on how distance teaching helped them participating in scientific practices, such as stating hypotheses and doing experiments are provided. Most respondents indicated agreement on that physics teaching at a distance do not encourage them develop their scientific practices skills $(\mathrm{Mdn}=1)$.

\section{Regarding Teacher-Student and Student-Student Communication and Teaching Practices}

Figure 4 includes students' answers regarding teacher-student communication compared to face-to-face teaching. Most students agree with the idea that the communication remained the same $(\mathrm{Mdn}=2)$ while there is a significant part of them who consider the communication got worse.

Figure 5 includes students' views regarding the communication with their classmates on issues related to the lesson. Results are similar to the previous question, revealing most students' agreement on the idea that communication remained the same $(\mathrm{Mdn}=2)$ while a considerable part of them think it got worse.

In Figure 6 students' views on how different the teacher's way of teaching was compared to face-to-face teaching are presented. According to students' answers, approximately $85 \%$ of the teachers differentiated their practices during physics teaching at a distance (if "little", "moderately", "much", and "very much" is added). 


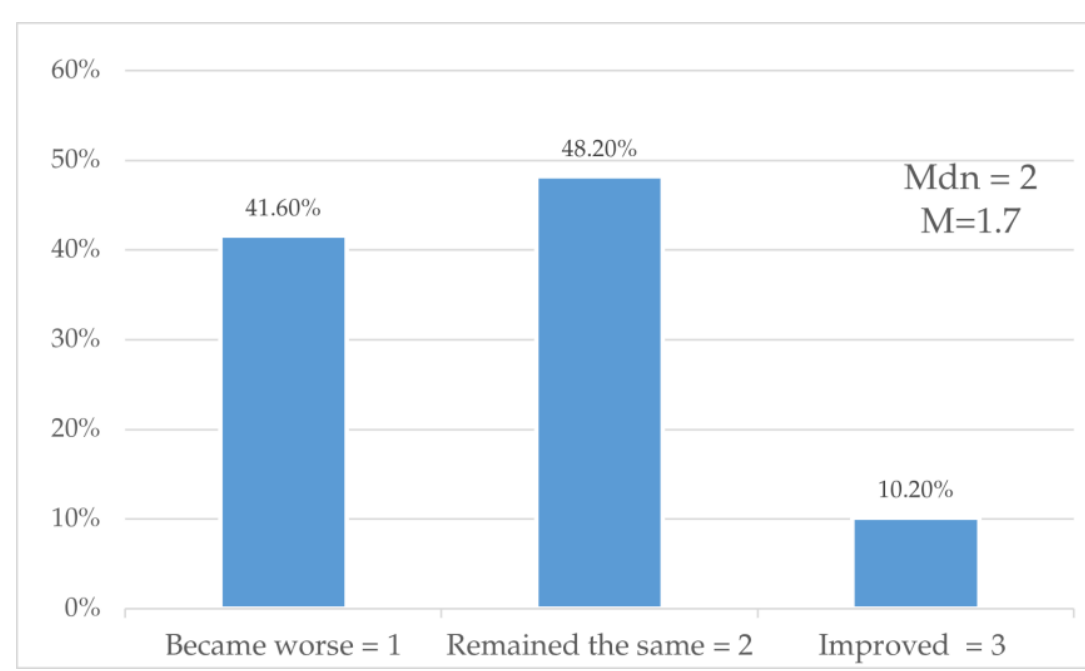

Figure 4. Teacher-student communication in the context of physics teaching at a distance

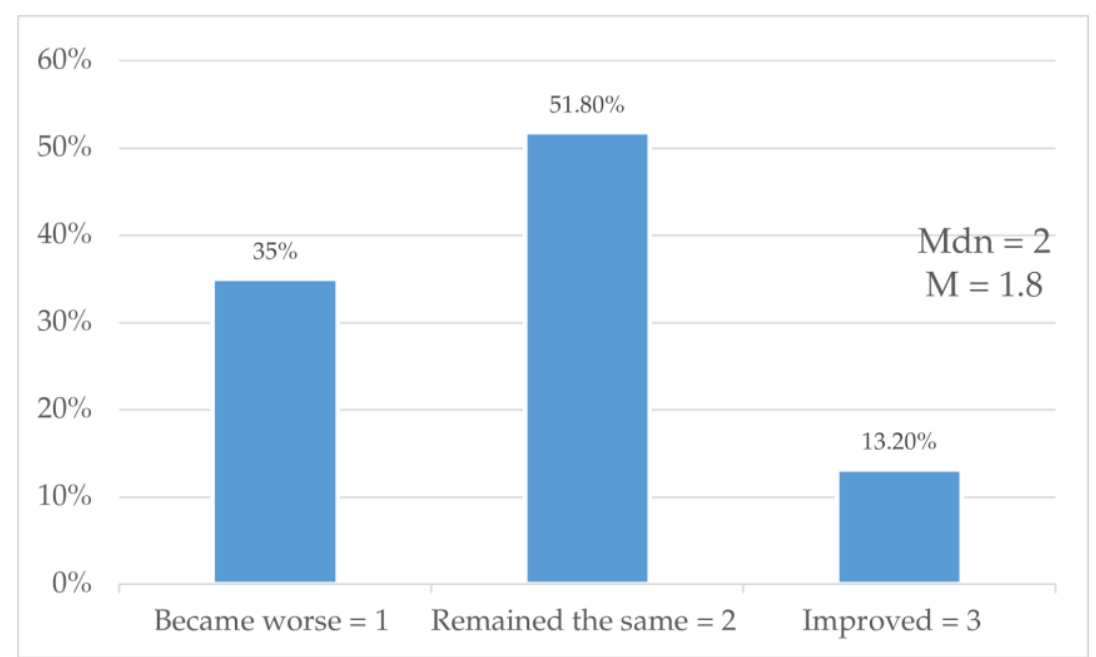

Figure 5. Student-student communication in the context of physics teaching at a distance

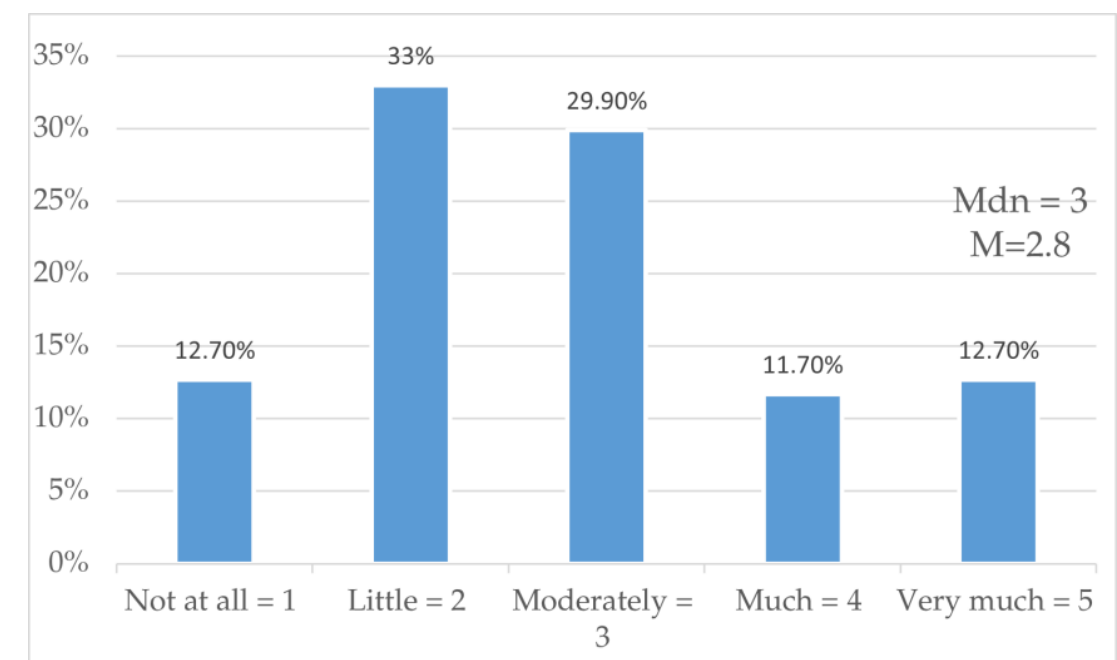

Figure 6. To what extent did teachers change their teaching practices during physics teaching at a distance? 


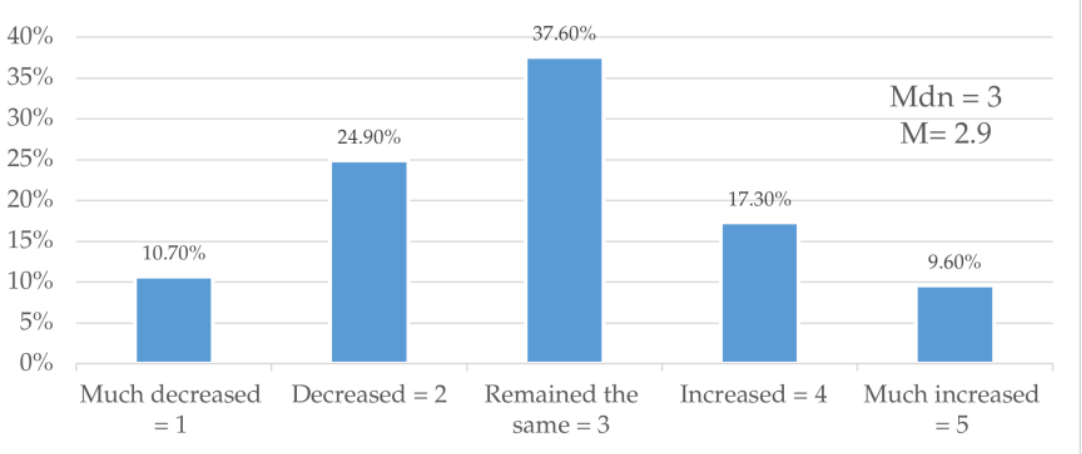

Figure 7. Homework in the context of physics teaching at a distance

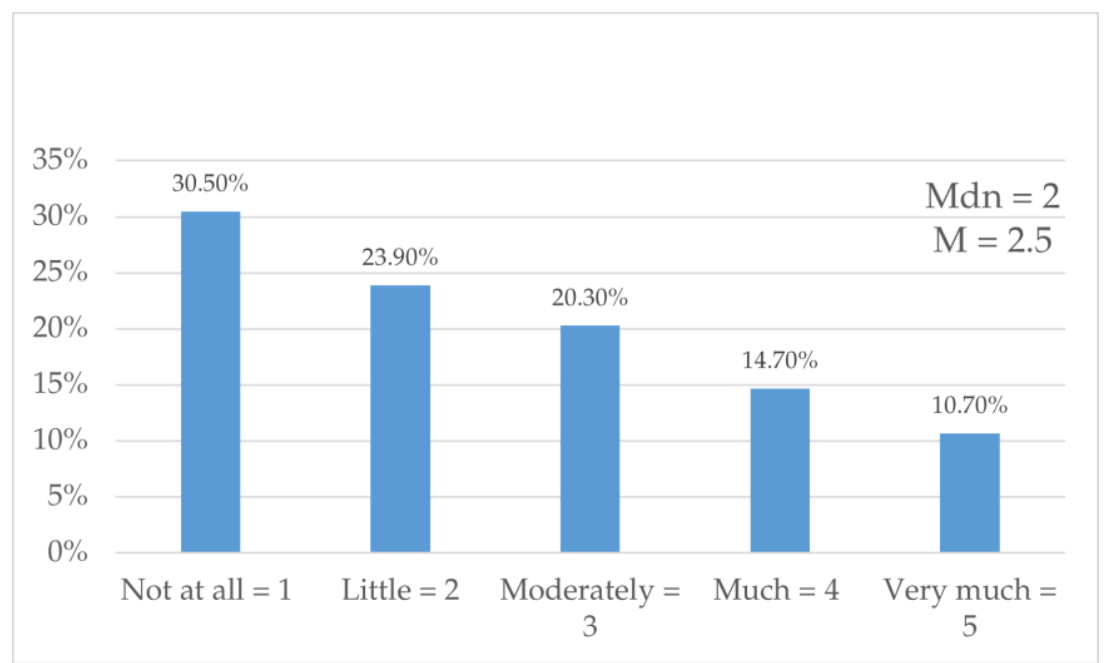

Figure 8. Was the way of taking feedback in distance physics lessons different than face-to-face lessons?

Figure 7 shows the amount of homework during physics distance teaching in comparison to face-to-face teaching. Therefore, most students considered homework demands either remained the same (37.6\%) or decreased (35.6\%) (if "much decreased" and "decreased" is added).

Figure 8 shows the differences in the way teachers provided feedback to students compared to face-toface teaching. Most students seem to agree that the way teachers provided feedback either remained the same or changed a little $(\mathrm{Mdn}=2)$. 


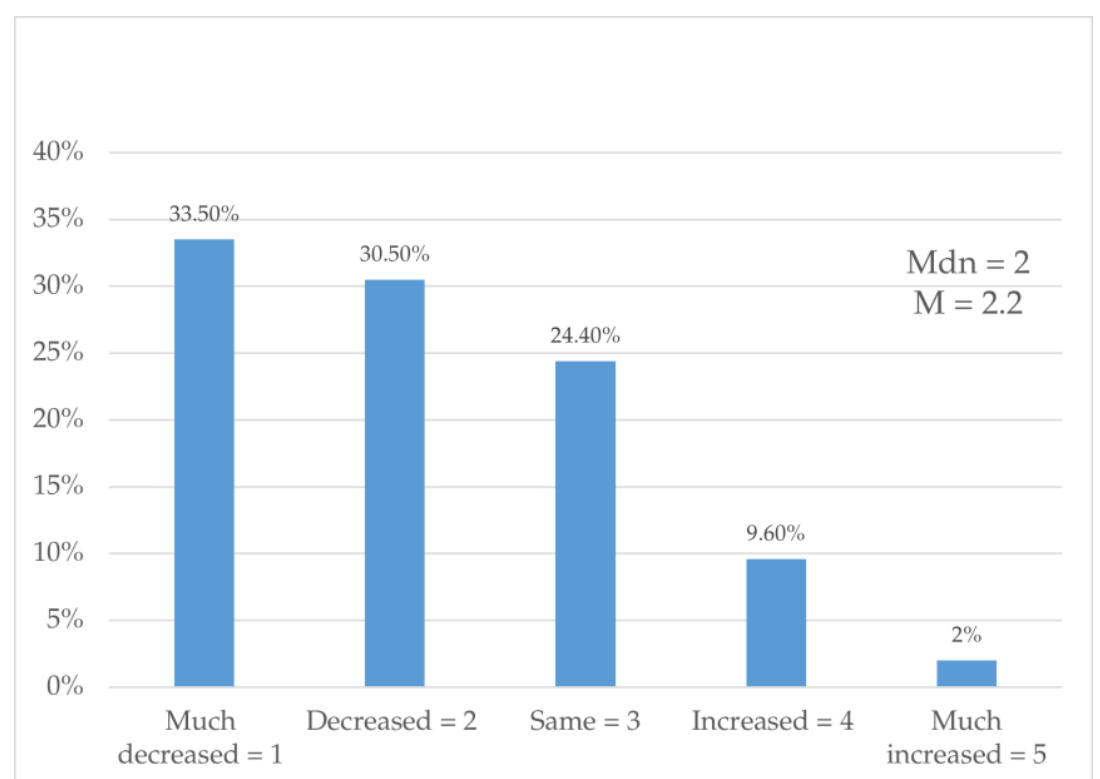

Figure 9. Students' concentration during distance teaching compared to face-to-face teaching

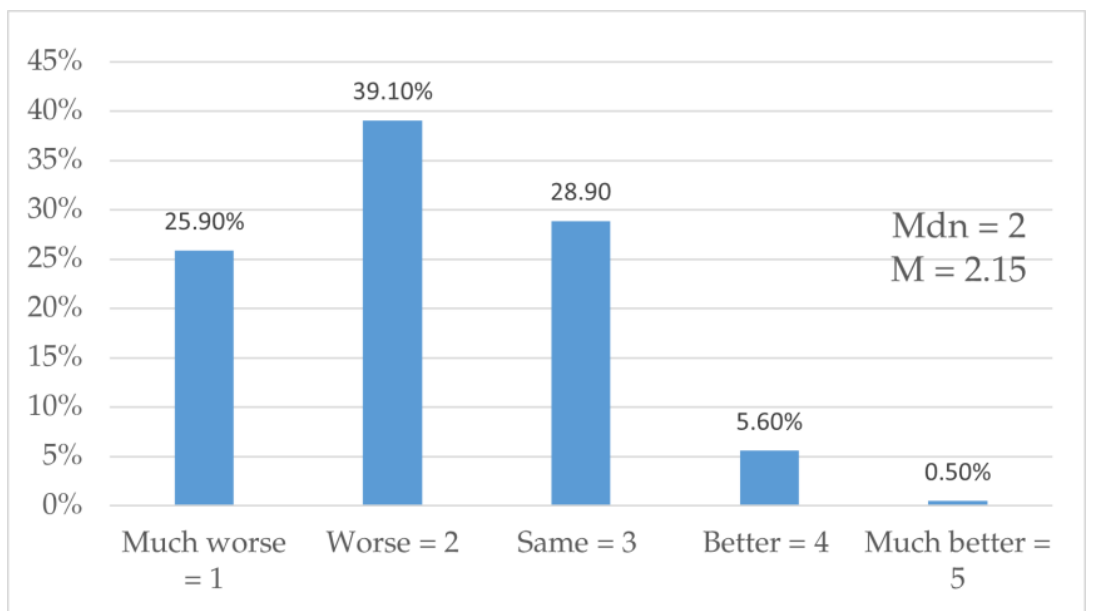

Figure 10. Conceptualizing physics lesson content during distance teaching compared to face-to-face teaching

\section{Regarding Students' Personal Engagement During Physics Teaching at a Distance}

In the fourth category of questions students were asked about parameters of physics teaching at a distance, such as their concentration during the lesson (Figure 9) and the understanding of new concepts (Figure 10). Most students claimed that they could not concentrate during distance teaching related to faceface teaching $(\mathrm{Mdn}=2)$ and that they had poor cognitive achievement $(\mathrm{Mdn}=2)$.

Finally, students were asked for an overall evaluation of the physics teaching at a distance in relation to face-face teaching (Figure 11). Students' answers reveal that the majority of them did not enjoy physics distance teaching $(\mathrm{Mdn}=1)$. 


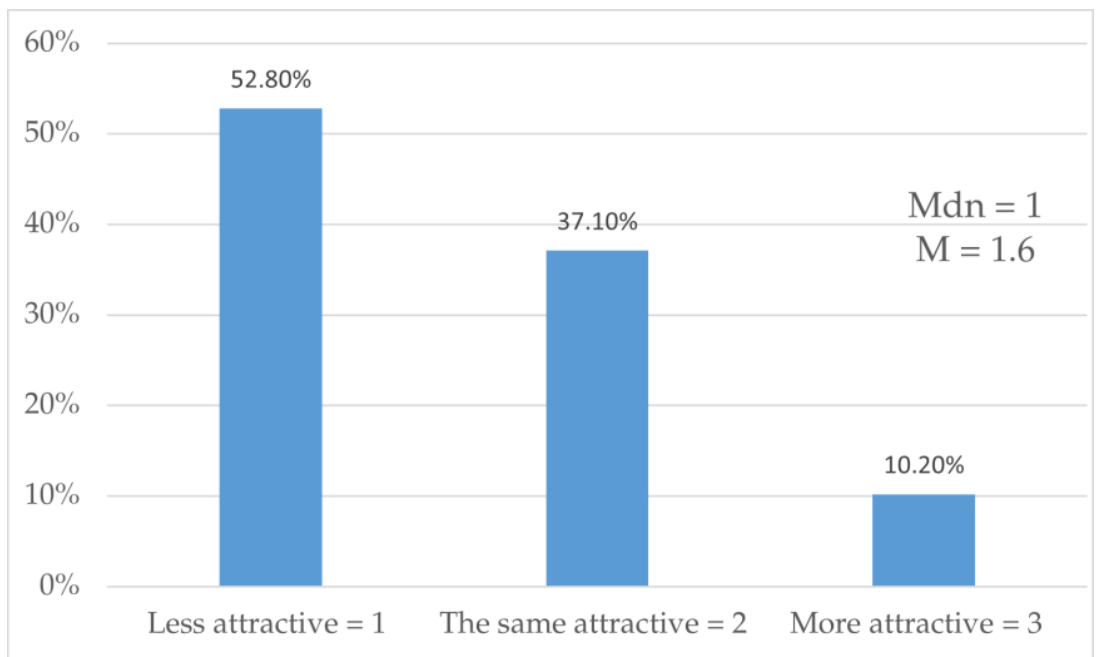

Figure 11. Overall evaluation of physics teaching at a distance related to face-to-face teaching

Table 1. What did you like during physics teaching at a distance?

\begin{tabular}{lcc}
\hline Answers & Percentage \\
\hline Audiovisual material (video, power point, digital stylus pen, etc.) & 38.2 & 36.2 \\
Nothing & 8.5 & \\
Teachers' effort to cope with the situation & 13.0 & 2.5 \\
Several facilities (shorter lesson hour, no face mask needed, the comfort of home, no school commuting) & 1.5 \\
Email communication with teachers & & \\
Other & & \\
\hline
\end{tabular}

Table 2. What did you not like during physics teaching at a distance?

\begin{tabular}{lc}
\hline Answers & Percentage \\
\hline Technical issues & 23.1 \\
Weak communication between classmates and teachers & 18.1 \\
I did not like anything & 13.6 \\
Ineffective teaching just to cover the material & 12.6 \\
Weak concentration & 10.0 \\
Several issues (way of examination, way some classmates were constantly noisy, too much homework, etc.) & 9.0 \\
Lack of experiments & 8.5 \\
I liked everything & 4.6 \\
No answer & 0.5 \\
\hline
\end{tabular}

Table 1 presents students' answers in the question "what did you like most during physics teaching at a distance", after indexing and categorizing. A percentage of $36.2 \%$ answered that they did not like anything during distance teaching of physics, which is indicative of the adolescent outrage over quarantine. A percentage of $38.2 \%$ of students reported that they liked the increased use of audiovisual material, such as video experiments, educational software, videos, presentations, pictures, etc. A percentage of $8 \%$ of the students appreciated teachers' attempts to cope with such difficult conditions that COVID-19 pandemic posed, and they recognized that teachers were much more lenient. A percentage of $13 \%$ pointed out as positive aspects of distance teaching several facilities such as the fact that they did not need to spend time for arriving to school. Finally, only the $2.5 \%$ of students found very interesting the fact that they could pose questions after lesson, via email communication with teachers.

Table 2 presents students' answers in the question "what did you not like during physics teaching at a distance" as they were formatted after indexing and categorization. A percentage of $13.6 \%$ of students answered that they did not like anything, while $4.6 \%$ of students stated that they "liked everything".

A significant percentage of students (23.1\%) reported experiencing technical problems with their internet connection, while $18.1 \%$ considered the lack of communication with the teacher and classmates and the lack of a classroom climate to be a major disadvantage. A percentage of $12.6 \%$ referred to ineffective teaching practices with the main symptom being the acceleration of the rhythm with the sole purpose of covering the 
curriculum and not the essential learning and familiarization with natural phenomena under consideration. A percentage of $10 \%$ said they had difficulty concentrating either because of personal weakness or because "the lesson is boring", while $9 \%$ pointed out various aspects of distance education that they did not like, such as the way of examination, the amount of homework and the continuous breaks of the lesson by different students. Only $8.5 \%$ were dissatisfied because of the lack of experiments and educational visits.

\section{DISCUSSION}

The study demonstrated students' views on distance physics education, organized in four categories-axes. Regarding the first category, which relates with technical difficulties and conditions in students' home environment, students expressed their concerns accordingly in the context of the open-ended questions, where technical issues seemed to be one of the main disadvantages of distance education. According to a student's answer "it was really bad not to be able either to hear or to be heard due to weak connection". Some of them also attributed the lack of student-student and student-teacher communication to the connection problems: "communication with classmates was limited, mainly due to poor connection". These findings are in accordance with research on teachers' views on distance education in the context of COVID-19 pandemic (Sari \& Nayir, 2020).

Regarding the second category, the content of the subject, students found the number of experimental activities had either not changed at all or had changed moderately, which implies that they might not do experiments either in physical class. Students were not encouraged participating in scientific practices such as hypothesis formation and doing experiments. Analysis of the open-ended questions revealed students' dissatisfaction regarding the weak existence of scientific practices and experimentation in class. On the other hand, students noticed the increased use of audio-visual material as a positive aspect of distance education, which is consistent with similar research on distance science education in primary education (Mandrikas et al., 2022).

The fact that experimental activities were decreased while the use of audio-visual material was increased make us think that audio-visual material may have been used in a rather passive way and not in active participation in e-class inquiries in order to enhance experimental procedures. These findings seem to contradict other research findings showing that distance laboratory teaching of physics through simulations (Sadaghiani, 2011) or through experiments that can be easily conducted in the homes of students (Gustafsson, 2002) have very good learning outcomes. However, such studies refer mainly to higher education and in cases where the curricula were pre-designed as distance or hybrid and were addressed to students who attended the program by choice and not in the context of compulsory education. It seems that the exceptional circumstances due to COVID-19 pandemic impose a much different context in which teachers and students had to adapt without any preparation, means or choice.

Regarding communication, it seems that distance teaching deprives students of exchanging views, asking questions, and giving clarifications, namely all the elements that give immediacy in the classroom. These findings are in accordance with students' answers in the open-ended questions (Table 2), where they highlight the lack of communication as the second most popular negative aspect of physics distance teaching. The analysis of open-ended questions gives evidence that students recognized as positive their teachers' effort to cope with the difficult situation of the COVID-19 pandemic but at the same time, they realized that the communication and concentration was weak at all levels. It generally seems that distance teaching did not encourage communication between teachers and students, nor between students. Similar results are shown by research from other educational settings either before (Gustafsson, 2002) or during the COVID-19 pandemic (Hebebci et al., 2020).

Moreover, students' answers reveal teachers' persistence on traditional practices, regarding the provision of feedback, which relates to the fact that teachers have not sufficient knowledge and experience about distance education in order to adapt to the new conditions. These results are consistent with relevant research on teachers' views and their need for distance education training during COVID-19 pandemic (Sari \& Nayir, 2020).

Regarding students' personal engagement during physics teaching at a distance, there was a clear trend in all the answers, which depicts that most students showed a much lower concentration in the remote class 
and in fact there were very few who achieved higher levels of concentration. It seems that distance teaching was not an adequate educational environment for the students to concentrate, at least in the context of COVID-19 pandemic, as it is also depicted in literature (Casacchia et al., 2021). Findings in physics' conceptualization are similar to concentration, as it seems that the achievement of the cognitive objectives of the physics lesson failed to a great extent. This failure can be attributed to the problems raised in the previous questions. Such problems include the lack of concentration due to the inappropriate home environment, the weak communication between teacher and students, as well as technical problems. The finding is confirmed through students answers in open-ended question about "what they did not like": "The lesson is as if the aim is to cover the material. Usually, I do not understand what it is all about". What students expressed, in their own words, is a need for curriculum adaptation in order the teaching material to become meaningful.

These findings deserve our attention, as some of them, such as the inadequacy of the students' home environment to participate in remote class and problems related to infrastructures, go much beyond educational research and lead to issues of wider social inequalities. This finding is consistent with other research related to tertiary education, that gives evidence that the shift to online education reinforced social inequalities (Devkota, 2021; Di Pietro et al., 2020).

Moreover, students' negative attitudes toward distance education could be attributed to factors related to COVID-19 pandemic and not to education per se, such as, prolonged restriction at home and social isolation, expressed in statements such as "it was very boring" or "I was constantly tired on the computer". Such statements indicate the emotional and psychological effects of fully remote learning. These results are consistent with relevant research on distance education during COVID-19 pandemic, in general and not only in physics (Hebebci et al., 2020) and at levels, other than high school (Almanar, 2020; Lemay et al., 2021).

\section{CONCLUSIONS}

This study aimed at mapping students' views of physics teaching at a distance. The findings revealed that students had mainly negative view of the physics remote class. Their point of view seemed to be influenced by the conditions prevailing in their home environment and the technical problems that occurred in the internet connection, the lack of communication between classmates and the teacher, and by the reduced experimental activities. However, several students found and pointed out some positive elements from the long period of distance education that referred either to the teaching of physics or to general topics. Such positive elements are the increased use of audiovisual material, which helped in the understanding of the concepts and processes of physics, and which could be adopted in the teaching of physics more broadly, and not only in the distance education.

The study indicated that students' challenges of physics teaching at a distance are similar to challenges of distance education in general. Therefore, it cannot be considered in isolation from the context of general distance education that prevailed almost entirely during the school year 2020-2021 in Greece due to the COVID-19 pandemic. Although we expected students to mostly refer to lack of experimentation and teachercentered teaching practices as the main problems, students' major problems with physics teaching at a distance was more general, such as the conditions in their home environment, the issues of poor connection and the lack of communication between teachers and students as well as students with each other. Such issues reinforce social inequalities and call for the adoption of policies that optimize the inclusive use of online education.

Even though the sample was limited and convenient, findings give rise to further research into the science teachers' views on distance teaching, how they faced the corresponding challenges and what kind of distance education training they found important. Moreover, findings give rise to further investigation in students' views from different socio-cultural backgrounds, as it seems that the great dissatisfaction of students arose from issues that were not so much related to the teacher and the process but to students' infrastructure. Finally, students' views ask for further research on science curricula adaptation to distance modalities in order distance teaching to lead to "learning" not only in the context of COVID-19 pandemic but in post-COVID-19 era also.

Author contributions: All authors were involved in concept, design, collection of data, interpretation, writing, and critically revising the article. All authors approve final version of the article. 
Funding: The authors received no financial support for the research and/or authorship of this article.

Declaration of interest: Authors declare no competing interest.

Data availability: Data generated or analyzed during this study are available from the authors on request.

\section{REFERENCES}

Almanar, M. (2020). The shifting of face-to-face learning to distance learning during the pandemic COVID 19. Globish: An English-Indonesian Journal for English, Education and Culture, 9(2), 119-127. https://doi.org/10. 31000/globish.v9i2.2779

Casacchia, M., Cifone, M. G., Giusti, L., Fabiani, L., Gatto, R., Lancia, L., Cinque, B., Petrucci, C., Giannoni, M., Ippoliti, R., Frattaroli, A. R., Macchiarelli, G., \& Roncone, R. (2021). Distance education during COVID 19: An Italian survey on the university teachers' perspectives and their emotional conditions. BMC Medical Education, 21, 335. https://doi.org/10.1186/s12909-021-02780-y

Center of Research and Documentation of Secondary Education Officials. (2021). Aspects of e-learning during the pandemic: Educational inequalities and implications for labor rights (in Greek). http://kemete.sch.gr

Devkota, K. R. (2021). Inequalities reinforced through online and distance education in the age of COVID-19: The case of higher education in Nepal. International Review of Education, 67, 145-165. https://doi.org/10.1007/s11159-021-09886-x

Di Pietro, G., Biagi, F., Dinis Mota Da Costa, P., Karpinski, Z., \& Mazza, J. (2020). The likely impact of COVID-19 on education: Reflections based on the existing literature and recent international datasets. JRC Publications Repository. https://publications.jrc.ec.europa.eu/repository/handle/JRC121071

Ferraro, V. F., Ambra, I. F., Aruta, L., \& lavarone, L. M. (2020). Distance Learning in the COVID-19 era: Perceptions in Southern Italy. Education Sciences, 10(12), 355. https://doi.org/10.3390/educsci10120355

Gewin, V. (2020). Five tips for moving teaching online as COVID-19 takes hold. Nature, 580, $295-296$. https://doi.org/10.1038/d41586-020-00896-7

Gray, J. A., \& Diloreto, M. (2016). The effects of student engagement, student satisfaction, and perceived learning in online learning. International Journal of Educational Leadership Preparation, 11(1), 98-119. https://files.eric.ed.gov/fulltext/EJ1103654.pdf

Gustafsson, P. (2002). Physics teaching at a distance. European Journal of Physics, 23(5), 469. https://doi.org/10.1088/0143-0807/23/5/303

Hebebci, M. T., Bertiz, Y., \& Alan, S. (2020). Investigation of views of students and teachers on distance education practices during the Coronavirus (COVID-19) pandemic. International Journal of Technology in Education and Science, 4(4), 267-282. https://doi.org/10.46328/ijtes.v4i4.113

Hedt, B., \& Pagano, M. (2011). Health indicators: Eliminating bias from convenience sampling estimators. Statistics in Medicine, 30, 560-568. https://doi.org/10.1002/sim.3920

Lemay, D., Bazelais, P., \& Doleck, T. (2021). Transition to online learning during the COVID-19 pandemic. Computers in Human Behaviour Reports, 4, 100130. https://doi.org/10.1016/j.chbr.2021.100130

Lincoln, Y. S., \& Guba, E. (1985). Naturalistic enquiry. SAGE. https://doi.org/10.1016/0147-1767(85)90062-8

Mandrikas, A., Stavrou, I., Kyriakou, K., Stefanidou, C., \& Skordoulis, C. (2022). Distance teaching and learning of Science during the COVID-19 pandemic in Greece: Views of K-6 students. Journal of Studies in Education, 12(1), 38-60. https://doi.org/10.5296/jse.v12i1.19463

Martin, E., \& Bolliger, D. U. (2018). Engagement matters: Students' perceptions on the importance of engagement strategies in the online environment. Online Learning, 22(1), $205-222$. https://doi.org/10.24059/olj.v22i1.1092

Mayring, P. (2000). Qualitative content analysis. Forum: Qualitative Social Research, 1(2), 20. https://doi.org/10.17169/fqs-1.2.1089

Mayring, P. (2015). Qualitative content analysis: Theoretical background and procedures. In A. BiknerAhsbahs, C. Knipping, \& N. Presmeg (Eds.), Approaches to qualitative research in mathematics education (pp. 365-380). Springer. https://doi.org/10.1007/978-94-017-9181-6_13

Meyer, K. (2019). Students' perceptions of face-to-face and online discussions: The advantage goes to... Online Journal of Distance Learning, 11(4), 53-69. https://doi.org/10.24059/olj.v11i4.1715 
Muzammil, M., Sutawijaya, A., \& Harsasi, M. (2020). Investigating student satisfaction in online learning: The role of student interaction and engagement in distance learning. Turkish Online Journal of Distance Education, 21, 88-96. https://doi.org/10.17718/tojde.770928

Polit, D. F., \& Beck, C. T. (2006). The content validity index: Are you sure you know what's being reported? Critique and recommendations. Research in Nursing \& Health, 29(5), 489-497. https://doi.org/10.1002/nur.20147

Radha, R., Mahalakshmi, K., Kumar, S., \& Saravanakumar, A. (2020). E-Learning during lockdown of COVID-19 pandemic: A global perspective. International Journal of Control and Automation, 13(4), 1088-1099.

Sadaghiani, H. R. (2011). Using multimedia learning modules in a hybrid-online course in electricity and magnetism. Physical Review Special Topics-Physics Education Research, 7(1), 1-7. https://doi.org/10.1103/PhysRevSTPER.7.010102

Sari, T., \& Nayir, F. (2020). Challenges in distance education during the (COVID-19) pandemic period. Qualitative Research in Education, 9(3), 328-360. https://doi.org/10.17583/qre.2020.5872

UNESCO. (2021). Supporting learning recovery one year into COVID-19. The global educator coalition in action. UNESCO. https://unesdoc.unesco.org/ark:/48223/pf0000376061

Watts, L. (2016). Synchronous and asynchronous communication in distance learning: A review of the literature. Quarterly Distance Education, 17(1), 23-32. 


\section{APPENDIX A}

\section{Questionnaire}

Date

School

Sex

Year of Birth

\section{Select the answer that fits most your opinion}

1. Quality of the inter-connection and general conditions in students' home environment

1.1. The prevailing conditions in your place during the distance teaching of physics, affected the lesson

\begin{tabular}{|c|c|c|c|c|}
\hline Very little & Little & Medium & Much & Very much \\
\hline
\end{tabular}

1.2. The quality of the inter-connection during the distance teaching of physics affected the lesson

\begin{tabular}{|c|c|c|c|c|}
\hline Very little & Little & Medium & Much & Very much \\
\hline
\end{tabular}

1.3. The device for the inter-connection during the distance teaching of physics affected the lesson

\begin{tabular}{|c|c|c|c|c|}
\hline Very little & Little & Medium & Much & Very much \\
\hline
\end{tabular}

\section{The content and the subject of the lesson}

2.1. How much are you interested in physics?

\begin{tabular}{|c|c|c|c|c|}
\hline Not at all & Slightly & Moderately & Very & Extremely \\
\hline
\end{tabular}

2.2. Did the number of experimental procedures you attended in physics teaching at a distance differ from the number of experimental procedures you attended or performed at school?

\begin{tabular}{|c|c|c|c|c|}
\hline Not at all & Little & Moderately & Much & Very much \\
\hline
\end{tabular}

2.3. To what extent do you agree with the phrase: "Distance teaching helped me making my own hypotheses and experimentally control them than face-to-face teaching."

\begin{tabular}{|c|c|c|c|c|}
\hline Not at all & Little & Moderately & Much & Very much \\
\hline
\end{tabular}

\section{Communication}

3.1. Communication between you and the teacher during distance teaching:

\begin{tabular}{|c|c|c|}
\hline Became worse & Remained the same & Improved \\
\hline
\end{tabular}

3.2. Communication between you and your classmates during distance teaching:

\begin{tabular}{|l|l|l|}
\hline Became worse & Remained the same & Improved \\
\hline
\end{tabular}

3.3. Did your teacher change teaching method during distance teaching compared to face-to-face teaching?

\begin{tabular}{|c|l|l|l|l|}
\hline Not at all & Little & Moderately & Much & Very much \\
\hline
\end{tabular}

3.4. Did the amount of homework during distance teaching differ from the amount of homework during the physics lesson in school?

\begin{tabular}{|c|c|l|l|l|}
\hline Much decreased & Decreased & Remained same & Increased & Much increased \\
\hline
\end{tabular}

3.5. Was the way of taking feedback in the distance physics lessons different than face-to-face lessons?

\begin{tabular}{|c|c|c|c|c|}
\hline Not at all & Little & Moderately & Much & Very much \\
\hline
\end{tabular}

\section{Personal engagement and involvement}

4.1. Your concentration during the physics teaching at a distance related to face-to-face teaching was

\begin{tabular}{|l|l|l|l|l|}
\hline Much decreased & Decreased & Remained same & Increased & Much increased \\
\hline
\end{tabular}


Stefanidou et al.

4.2. Do you think that physics teaching at a distance helped you conceptualize the content of the lesson? \begin{tabular}{|l|l|l|l|l|}
\hline Much worse & Worse & Remained same & Better & Much better \\
\hline
\end{tabular}

4.3. Do you find physics teaching at a distance related to face-to-face teaching?

\begin{tabular}{|l|l|l}
\hline Less attractive & The same & More attractive
\end{tabular}

4.4. What did you like most in physics distance teaching? (You may refer to more than one aspect you liked in distance education)

4.5. What did you not like at all in physics distance education? (You may refer to more than one aspect you did not like) 